\title{
MEDICALIZAÇÃO DA EDUCAÇÃO: INVESTIGAÇÕES ACERCA DA PRODUÇÃO BIBLIOGRÁFICA BRASILEIRA
}

\author{
Laura Norat de Lima" \\ Maria Lúcia Chaves Lima**
}

RESUMO: Atualmente, todas as formas de agir, de se desenvolver ou (não) aprender são passíveis de um diagnóstico. O cenário apresentado é chamado por diversos/as autores/as como medicalização da educação, compreendida como um processo de transformar questões não-médicas, ou seja, de origem social, em questões médicas. Diante desse contexto, o presente estudo objetivou analisar a produção bibliográfica nacional sobre a temática da medicalização da educação. A base de dados para a busca de artigos foi a Scientific Eletronic Library Online (SciELO Brasil), utilizandose a combinação de quatro descritores: medicalização, patologização, educação, escola. Foram encontrados 45 artigos de temas diversos, dentre os quais 13 discutem mais especificamente a medicalização relacionada à educação escolar. A análise foi conduzida pelo ano de publicação, pelas áreas de conhecimento do/as autores/as, os periódicos publicados, os campos de interesse das pesquisas, o público alvo de preocupação desses autores/as etc. Verificou-se que as produções textuais sobre o tema iniciam em 2003, tendo os maiores índices de publicações a partir de 2012. Em relação à formação dos/as autores/as, destaca-se a área de Psicologia como a responsável pela maior quantidade de profissionais que escrevem sobre o tema. Desse modo, percebe-se a ainda incipiente inserção de profissionais da Pedagogia na problematização sobre medicalização, mesmo este processo sendo tão presente no contexto educacional. De todo modo, percebe-se um crescente interesse por essa temática, promovendo críticas sobre as formas de viver e propondo um novo olhar no sentido da desmedicalizar a vida e a educação.

PALAVRAS-CHAVE: Medicalização; Educação; Psicologia educacional; Análise.

\section{MEDICALIZATION OF EDUCATION: INVESTIGATION ON BIBLIOGRAPHIC PRODUCTION IN BRAZIL}

\begin{abstract}
All types of activities, development, learning or (non)learning are currently being diagnosed. Several authors tagged this scenario as the medicalization of education, or rather, the transformation of social (non-medical) issues into

Graduanda do curso de Pedagogia pela Universidade Federal do Pará, Brasil. E-mail: noratlaura1@gmail.com

* Doutora em Psicologia Social pela Pontifícia Universidade de São Paulo. Docente do Programa de Pós-Graduação em Psicologia e do Instituto de Ciências da Educação da Universidade Federal do Pará (UFPR), Brasil.
\end{abstract}


medical issues. Current analysis investigates the bibliographic production in Brazil on the medicalization of education. The Scientific Electronic Library Online (SciELO Brasil) was the database from which articles were retrieved by combining four descriptors: medicalization, pathologization, education, school. Forty-five articles on several themes were detected, out of which 13 discussed specifically medicalization related to school education. Analysis was conducted by the year of publication, knowledge areas of authors, journals, research field of interest, the target public and others. Textual productions on the theme started in 2003, with highest rates since 2012. Psychologists were the most numerous to write on the subject. However, one may perceive the timid insertion of pedagogues problematizing medicalization, even though the process is greatly present in the educational context. There is a growing interest in the theme with a critique on the type of living and proposals for a new view on the de-medicalization of life and education.

KEY WORDS: Medicalization; Education; Educational psychology; Analysis.

\section{INTRODUÇÃO}

Não é difícil escutar que as crianças e adolescentes de hoje em dia não apresentam o mesmo padrão de comportamento de antigamente. Cada vez mais ágeis, inquietos demais ou tímidos demais, desafiadores, eles configuram modos diversos de ser e viver. Neste contexto, é necessário lembrar que vivemos em uma sociedade que institui regras e padrões de condutas de como o ser humano deve agir, comportar-se e até mesmo como eles - as crianças e os adolescentes - devem se desenvolver.

Aqueles que não apresentam comportamentos considerados "normais", ou seja, que destoam do ambiente educacional, muitas vezes são diagnosticados como possuidores de alguma patologia. Observa-se, na atualidade, um crescimento dos números de diagnósticos ofertados à crianças e adolescentes que não aprendem nos conteúdos formais da escola, que não se comportam ou interagem com os demais como desejado etc. Tal processo é chamado por alguns autores como medicalização da educação.

A medicalização da educação pode ser entendida pela expansão da jurisdição médica para o âmbito dos processos educacionais. Para Collares e Moysés (1994, p. 
25), a medicalização da educação se dá pelo "processo de transformar questões nãomédicas, eminentemente de origem social e política, em questões médicas”, ou seja, as inquietações, conflitos, tensões, perturbações que estes sujeitos experimentam e apresentam no cotidiano da sala de aula passam a ser interpretadas como doenças e que levam supostamente ao insucesso e fracasso escolar.

Autista, disléxico, hiperativo - entre outras doenças que rondam o contexto educacional - são algumas das rotulações atribuídas para estes indivíduos. Dado tal diagnóstico, essas crianças e adolescentes acabam internalizando estes rótulos, construindo sua personalidade acreditando que são doentes, incapazes e que necessitam sempre de auxílio e tratamento para dar conta das exigências escolares.

De acordo com Meira (2012, p. 136), a medicalização da educação ocasiona uma "epidemia de diagnósticos", produzindo também uma "epidemia de tratamentos", transformando pessoas com características consideradas problemáticas (desatenção, agitação, dificuldade de aprender etc.) em pacientes.

Tendo em vista que a medicalização cresce no âmbito educacional, a presente pesquisa teve a intenção de investigar de que forma o tema tem sido abordado e fomentado dentro das produções científicas nacionais, realizando uma revisão da literatura nacional.

Sendo assim, o objetivo geral desse estudo foi analisar a produção bibliográfica brasileira que tem como tema a medicalização da educação, identificando o que têm sido objeto de análise dentro do contexto, além de mapear a rede de forças existente nas produções sobre o processo de medicalização da educação (autores/as, áreas de interesse, público-alvo da preocupação, referenciais teóricos e metodológicos utilizados etc.).

\section{METODOLOGIA}

Para analisar como a medicalização tem sido debatida no cenário científico e educacional, realizou-se um mapeamento dos artigos científicos publicados no Brasil sobre o tema. Para isso, optou-se pela base de dados da Scientific Eletronic Library Online (SciELO Brasil), uma vez que esta biblioteca eletrônica abrange uma ampla coleção de periódicos científicos brasileiros, além de seu potencial em armazenar e disseminar a produção científica em formato eletrônico, mostrando-se uma fonte privilegiada para atingir os objetivos da presente investigação, além de 
nos proporcionar navegar por inúmeros periódicos que não são ligados apenas à área de educação e sim de áreas como saúde, psicologia, entre outros.

Para realizar a busca pelos periódicos, utilizou-se quatro descritores: medicalização, educação, escola e patologização de forma combinada. Estes descritores deveriam estar presentes no título, assunto ou resumos destas publicações. A partir dessa busca, foram encontrados 45 artigos e uma carta, sendo que esta última se apresenta mais como uma nota de esclarecimento.

Dos 45 artigos encontrados com os descritores acima apresentados, apenas 13 trouxeram uma discussão específica sobre a medicalização da educação, sendo os demais artigos excluídos, pois voltavam suas discussões a outras áreas, tais como saúde da mulher, saúde materno-infantil, violência de gênero e contra a criança, entre outros assuntos.

A análise textual dos artigos científicos foi orientada por alguns elementos, tais como: ano de produção, formação dos autores, periódicos publicados, os campos de interesse das pesquisas, o público alvo de preocupação desses autores, entre outros.

\section{ANÁLISE DAS INFORMAÇÕES}

\subsection{ANO DE PUBLICAÇÃO}

O levantamento do ano de publicação das produções - o primeiro aspecto analisado - não estabeleceu a priori um período cronológico inicial, apenas o período final, 2014, ano que coincide com o início da presente pesquisa. Conforme o gráfico 1 , foram identificadas publicações no período compreendido entre 2003 a 2014, totalizando doze anos. 
- Produção

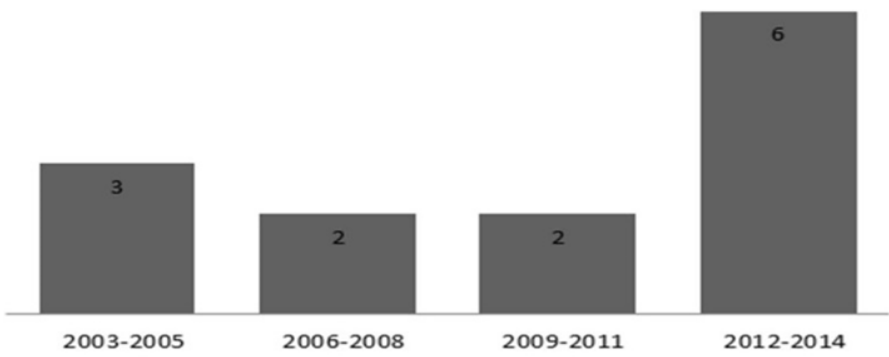

Gráfico 1. Análise relativa ao ano de publicação e produção textual Fonte: Dados da pesquisa

Para analisarmos essas publicações em seu aspecto cronológico, escolhemos agrupá-las por triênios, tomando como referência a forma de periocidade usada pela CAPES $^{3}$, órgão regulador e avaliador da produção de pesquisa e pós-graduação no Brasil.

Desse modo, percebe-se que as produções que trazem ao centro do debate o fenômeno da medicalização da educação e que constam na base do SciELO, iniciamse a partir de 2003. Entre os anos de 2003 e 2005, três artigos científicos foram produzidos. Nos triênios de 2006 a 2008 e 2009 a 2011, encontramos apenas duas produções para cada triênio. Já entre 2012 a 2014, encontramos um crescimento na produção de artigos acerca do tema, uma vez que há seis artigos publicados.

O que se percebe a partir desse panorama é que antes de 2003 o debate específico sobre a medicalização da educação ainda não era alvo de publicações nacionais. Mesmo a partir dessa data, ainda há um incipiente interesse em se problematizar o tema, o que é constatado na reduzida quantidade de produções publicadas nos períodos de 2003 a 2011.

Essa pouca expressividade na produção pode ser interpretada pelo fato de que em tempos passados a instituição escolar e seus profissionais não interpretavam o fracasso escolar de seus alunos como um problema voltado ao fator biológico, havendo poucas produções de diagnósticos e tratamentos, logo, este fenômeno raramente era encontrado dentro do contexto educacional.

A CAPES tinha periodicidade trienal na avaliação da produção dos pesquisadores dos programas de pósgraduações, mas recentemente passou a quadrienal. 
Atualmente, ao contrário a pouca produção de diagnósticos e rotulações de épocas passadas, a instituição escolar, infelizmente, necessita cada vez mais de um diagnóstico para justificar a questão do não aprender de certo aluno, recorrendo ao uso de medicamentos para tratar supostas patologias que estes apresentam. Porém, é digno de nota que a partir de 2012 há um crescimento no número de artigos voltados à medicalização da educação. Não se trata de um aumento expressivo, é certo, mas pode indicar uma maior preocupação com o número de diagnósticos, rotulações e medicalizações que circulam no ambiente educacional.

\subsection{PERIÓDICOS}

Relacionado aos periódicos em que foram publicados os artigos, percebemos que estes discutem áreas que permeiam o campo da educação, psicologia, sociedade, linguísticas, entre outros. A relação dos periódicos e quantidades de artigos publicados em cada um está apresentada no gráfico abaixo:



Gráfico 2. Relação dos periódicos e quantidades de artigos publicados Fonte: Dados da pesquisa

Entre os dez periódicos que trazem os artigos alvo desta pesquisa, foram encontrados apenas três específicos da área da educação: "Educação e Pesquisa"; "Educação e Sociedade", e "Educação em Revista".

No que tange à área de psicologia, foram encontrados quatro periódicos que discutem elementos referentes às principais áreas, porém, não deixam de lado a discussão de assuntos pertinentes ao contexto educacional. 
Foi encontrado um artigo na área de enfermagem, no periódico "Revista da Escola de Enfermagem da USP", que propõe trabalhar com artigos científicos voltados para um melhor desempenho profissional e novas propostas para os fundamentos do ensino de enfermagem. Há dois artigos no periódico "Trabalhos em Linguística Aplicada" que discute o processo de ensino-aprendizagem nas áreas de linguística. Há ainda um voltado para as discussões de gênero, publicado no periódico "Cadernos Pagu".

Percebe-se, desse modo, que a medicalização é um tema interdisciplinar. Mesmo que o estudo sobre o fenômeno da medicalização esteja voltado para a área de educação, é possível compreender que este vem sendo discutido para além do contexto educacional, haja vista na quantidade de periódicos que estão publicando sobre o tema, o que o torna um ponto para o debate.

\section{3 ÁREA DE FORMAÇÃO DOS AUTORES E AUTORAS}

Essa categoria de análise tem o intuito de conhecer quais os/as profissionais que se dedicam à medicalização da educação. Optou-se por destacar a formação de origem dos autores dos artigos, ou seja, a organização das áreas de formação se deu através da graduação dos mesmos.

Foram encontradas sete áreas que permeiam o campo de instrução dos autores: Psicologia, Enfermagem, Fonoaudiologia, Educação Física, Letras, Odontologia e Farmácia, como apresentado no gráfico a seguir:

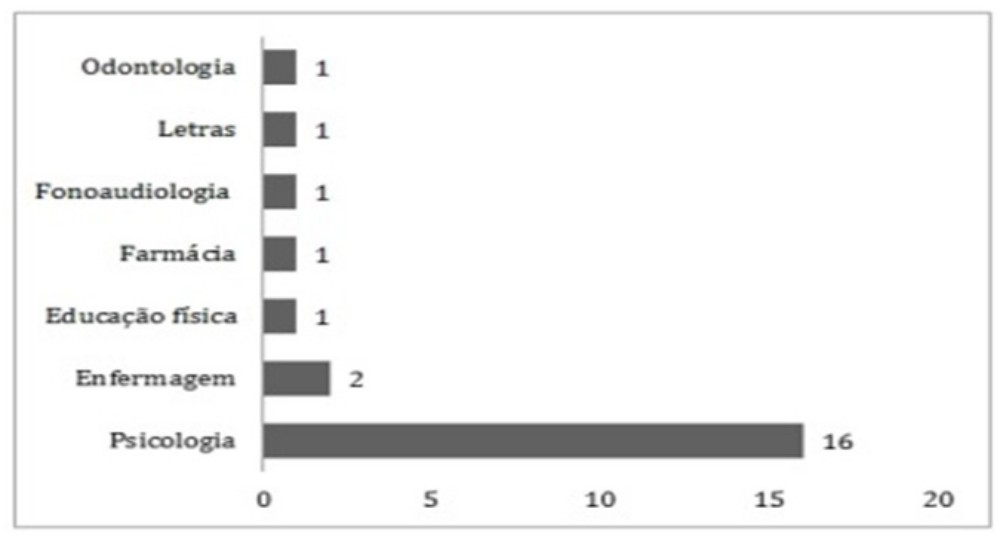

Gráfico 3. Área de formação dos autores

Fonte: Dados da pesquisa 
A maior parte dos/as profissionais que discutem acerca do tema provém da área de Psicologia. É interessante notar que profissionais de áreas que trabalham em conjunto com a educação, como a psicologia, entre outros, estejam cada vez mais ativos ao debater a medicalização da educação, fazendo com que haja discussão, reflexão e críticas contrárias aos processos de diagnósticos, rotulações e medicalização, propondo um novo olhar e modos de se desmedicalizar a educação.

No entanto, chama atenção a ausência de profissionais da área da Pedagogia nesta pesquisa exploratória. Por que estes/as profissionais não estão envolvidos neste debate, sendo que cada vez mais a medicalização está fortemente presente nas salas de aula?

Acredita-se que seja urgente que os profissionais de pedagogia passem a se envolver nesta discussão, haja vista que os mesmos encontram-se como sujeitos ativos dentro do ambiente educacional.

\subsection{CAMPO DE INTERESSE}

Identificou-se três grandes campos de interesse: "educação escolar"; "educação e saúde"; "gênero e sexualidade na educação".

No campo de interesse sobre "educação escolar", encontramos cinco artigos que discutem como a medicalização da educação está sendo construída, trazendo a problemática sobre como o discurso médico vem ganhando cada vez mais espaço no contexto da educação. As produções são:

Quadro 1. Produções que integravam o campo de interesse "educação escolar"

DECOTELLI, K. M.; BOHRER, L. C. T.; BICALHO, P. P. G. A Droga da obediência: medicalização, infância e biopoder - notas sobre clínica. Psicologia: Ciência e Profissão, v. 33, n. 2, 2013.

GUARIDO, R. A Medicalização do sofrimento psíquico: considerações sobre o discurso psiquiátrico e seus efeitos na educação. Educação e Pesquisa, São Paulo, v. 33, n. 1, p. 151-161, jan./abr. 2007.

GUARIDO, R.; VOLTOLINI, R. O que não tem remédio, remediado está? Educação em Revista, Belo Horizonte, v. 25, n. 1, p. 239-263, abr. 2009.

HASHIGUTI, S. T. O Discurso médico e a patologização da educação. Trabalho em Linguística Aplicada, Campinas, v. 48, n. 1, p. 41-51, jan./jun. 2009.

SIGNOR, R. Transtorno de Déficit de Atenção e Hiperatividade: uma análise histórica e social. RBLA, Belo Horizonte, v. 13, n. 4, p. 1145-1166, 2013.

Fonte: Dados da pesquisa 
Os artigos englobados nesta categoria ressaltam que o uso de diagnósticos se faz cada vez mais presentes para dar respostas aos problemas que o/a estudante apresenta. Os textos trazem consigo argumentos pertinentes sobre as formas de esquadrinhamentos da vida escolar e o aumento significativo na prescrição de medicamentos psiquiátricos para tratar problemas que, diversas vezes, não são de ordem biomédica e sim, social e mesmo escolar.

A respeito do campo de interesse "educação e saúde", foram encontrados sete artigos:

Quadro 2. Produções que integravam o campo de interesse "educação escolar" BELTRAME, M. M.; BOARINI, M. L.; Saúde mental e infância: reflexões sobre a demanda escolar de um CAPSi. Psicologia: Ciência e Profissão, v. 33, n. 2, p. 336-349, 2013.

CARVALHO, T. R. F.; BRANT, L. C.; MELO, M. B. de. Exigências de produtividade na escola e o consumo de metilfenidato. Educação e Sociedade, Campinas, v. 35, n. 127, p. 587-604, abr./ jun. 2014.

HECKERT, A. L. C.; ROCHA, M. L. da. A Maquinaria escolar e os processos de regulamentação da vida. Psicologia \& Sociedade, v. 24, n. spe, p. 85-93, 2012.

MEIRA, M. E. M.; Para uma crítica da Medicalização na educação. Revista Semestral da Associação Brasileira de Psicologia Escolar e Educacional, SP, v. 16, n. 1, jan.jun. 2012.

NAKAMURA, M. S. et al. Desvendando a queixa escolar: um estudo no Serviço de Psicologia da Universidade Federal de Rondônia. Revista Semestral da Associação Brasileira de Psicologia Escolar e Educacional, SP, v. 12, n. 2, p. 423-429, jul./dez. 2008.

TOASSA, G. Sociedade Tarja Preta: uma crítica à medicalização de crianças e adolescentes. Fractal Rev. Psicol., v. 24, n. 2, p. 429-434, maio/ago. 2012.

VARGENS, O. M. da C.; PROGIANTI, J. M. O Processo de desmedicalização da assistência à mulher no Ensino de enfermagem. Rev. Esc. Enferm USP, v. 38, n. 1, p. 46-50, 2004.

Fonte: Dados da pesquisa

Nestas produções, a medicalização da educação é discutida por uma ótica mais voltada ao campo da saúde, problematizando como o saber biomédico foi construído historicamente dentro do contexto educacional. Trabalham sobre a expansão progressiva de intervenção da saúde, redefinindo as experiências e comportamentos que os/as estudantes apresentam. Há também a crítica do lucro que a indústria farmacêutica alcança com o crescimento destes diagnósticos. 
Vale ressaltar que apenas um artigo foi categorizado no campo de interesse "gênero e sexualidade na educação". Trata-se da produção escrita por Helena Altmann (2003), intitulada "Orientação sexual em uma escola: recortes de corpos e de gênero", publicada no Cadernos Pagu. Esta produção vem destacar a disciplinarização e medicalização do corpo feminino em conjunto com métodos preventivos contra a gravidez dentro do ambiente educacional.

\subsection{SUJEITOS DA ANÁLISE/ALVO DE PREOCUPAÇÃO}

Identificou-se os indivíduos e/ou instituições para os quais estes artigos voltavam a sua atenção ao discutir o processo de medicalização. Desse modo, observou-se que os artigos destinavam suas atenções para crianças, adolescentes, adultos, discentes e docentes, CAPSi, dentre outros.

Foi possível identificar que certas produções traziam em seu debate as crianças como alvo de preocupação, visando problematizar como elas estão sendo construídas quanto ao saber biomédico, visando saber como os processos de diagnósticos e medicalização interferem em sua vida no contexto educacional.

Outros artigos também englobaram os/as adolescentes, juntamente com as crianças, na crítica à produção de diagnósticos desses indivíduos dentro do ambiente educacional. Há também artigos que versam sobre crianças, adolescentes e professores como os alvos de preocupação deste fenômeno, mostrando as diversas faces e a influência que a medicalização exerce sobre a educação.

Um artigo teve como foco os discentes e docentes do curso de enfermagem da UFRJ, alvos de preocupação para a construção de um novo currículo para seu curso, dando ênfase ao processo de desmedicalização. Outro artigo chama a atenção para o consumo do medicamento metilfenidato entre crianças e adultos, como forma de suprir as exigências de produtividades que estes sofrem, seja nos estudos ou no trabalho.

Ainda foi possível encontrar professores e demais profissionais da educação como alvo da preocupação das publicações, com o objetivo de expor como estes profissionais estão compactuando com o saber médico para explicar o fracasso escolar dos/as estudantes. 
Por fim, uma instituição também foi alvo da atenção de um artigo. Trata-se do Centro de Atenção Psicossocial Infantil - CAPSi. A preocupação concentrava-se na grande demanda que o CAPSi recebia de crianças que apresentavam problemas referentes à aprendizagem e ao seu comportamento, expondo assim como são construídos os processos de patologização e medicalização, dentro do ambiente educacional e no Centro de Atenção Psicossocial Infantil.

\subsection{DEFINIÇÕES DE MEDICALIZAÇÃO}

Dos 13 artigos analisados, constatou-se que todos trabalham o conceito de medicalização, porém, alguns traziam a definição de forma clara e concisa e em outros, este conceito não se apresentava de forma direta.

Há semelhanças e diferenças entre as definições trazidas pelos artigos. Entre as semelhanças encontradas, verificou-se que entre as 13 publicações, 7 delas apresentavam a definição de medicalização voltada a um contexto mais amplo, preocupando-se em expor um contexto mais social do que especificamente educacional.

Nestas publicações a definição foi apresentada como um processo por meio do qual são deslocados para o campo médico, problemas que fazem parte do cotidiano dos indivíduos. Desse modo, fenômenos de origem social e política são convertidos em questões biológicas, próprias de cada indivíduo.

Outra semelhança é relativa ao conceito de medicalização voltado a área da educação. As definições apresentadas pontuam o fenômeno da medicalização como a expansão da jurisdição médica para o âmbito dos processos educacionais, transformando em casos médicos as inquietações, perturbações, conflitos e tensões experimentados no processo do aprender e da convivência no espaço escolar.

\subsection{CRÍTICAS E CONTRIBUIÇÕES}

No universo dessa pesquisa sobre medicalização ficou claro a preocupação por parte dos autores em expor uma série de problemáticas do cotidiano escolar e infantil. Os autores criticam a relação dos problemas escolares a problemas médicos. 
Há um alerta para a expansão dos diagnósticos psiquiátricos para os estudantes que apresentam algum comportamento indesejado na escola. Os diagnósticos se tornam a tábua de salvação de um suposto não-saber dos educadores frente às situações que emergem na escola.

Há críticas voltadas também ao sistema educacional brasileiro, que reproduz práticas segregadoras e opressoras, bem como o regime disciplinar, que culpabiliza o indivíduo ou sua família, denominada "desestruturada", pelo seu fracasso escolar.

Todos os envolvidos - professores, psicólogos, médicos - parecem não refletir sobre como está sendo construído a legitimação de "doenças" dentro do contexto educacional, isto é, quase nunca se estranha como a escola tem produzido suas próprias patologias, seus encaminhamentos e suas curas.

Outra crítica pertinente é quanto ao aumento significativo na prescrição de medicamentos psiquiátricos e a extensão dessa lógica de tratamento como prática nas escolas, propondo que os medicamentos compõem a única resposta aos porquês do não-aprendizado, deixando de lado o papel que deveria ser exercido pelos professores, o de ensinar.

Desse modo, denuncia-se a indústria farmacêutica e seu interesse puramente financeiro na venda de remédios, esquecendo-se, portanto, dos indivíduos associados a esses supostos tratamentos.

Já no âmbito das contribuições, os artigos apresentavam argumentos que levam à problematização de como este processo de medicalização não atinge somente estudantes, mas sim, diversas áreas: adultos que desejam um rendimento melhor no trabalho, pessoas que tem insônia e passam a ser tratadas como possuidoras de um distúrbio do sono, ou as que estão tristes por algum acontecimento traumático, mas logo são taxadas como deprimidas etc. Ou seja, a medicalização é um fenômeno que abarca diversas esferas da vida social, não restringindo-se ao campo educacional.

Entre essas reflexões foi possível encontrar novas ideias no que tange à maneira de se analisar a questão da não-aprendizagem, propondo discussões sobre novos meios de intervenção para lidar com a educação.

\section{CONSIDERAÇÕES FINAIS}

Conclui-se que a medicalização da educação se torna cada vez mais frequente e preocupante, pois se vive em uma sociedade disposta de regras e padrões de 
condutas, na qual há uma normatização da vida e até mesmo um esquadrinhamento da vida escolar.

Cada vez mais pessoas preferem buscar soluções rápidas, como um medicamento, objetivando resultados rápidos, em detrimento de métodos educativos para tratar o problema do não aprender, já que é muito mais cômodo para pais, professores e profissionais medicalizar o indivíduo.

Medicalizar e culpar o indivíduo que não aprende é mais fácil do que interpretar o real problema que este aluno vem enfrentando, esquecendo que tal prática medicalizante acarreta um grande prejuízo na socialização e na relação de ensino e aprendizagem do aluno.

A reflexão sobre os modos de ensinar, técnicas e metodologias dificilmente são questionadas, pois a tentativa de mudar paradigmas educacionais também esbarra nas dificuldades encontradas no cotidiano escolar, seja no método de ensino tradicional, seja pelo acompanhamento desses alunos pelos pais.

Diante de um aprendizado uniforme, cíclico e impessoal, a medicalização parece ser a solução imediata para uniformizar e alinhar as crianças às necessidades dos adultos e dos sistemas de ensino, o que de forma lógica, faz com que a indústria farmacêutica entre no debate, pois a mesma não pretende solucionar o problema aqui levantado, e sim, dar a solução que os adultos e "rotuladores" necessitam.

Com a análise das produções textuais coletadas nesta pesquisa, percebese o quanto o saber médico se entranhou na educação e o quanto o processo de normalização da medicalização ganha mais força, no qual diagnosticar e rotular se tornaram práticas em crescente fortificação dentro do espaço escolar.

O que ficou claro neste estudo, é a dedicação dos autores em expor a problemática de uma forma que o leitor possa refletir sobre como o fenômeno da medicalização ganha cada vez mais espaço, dentro do âmbito educacional e o quão grave está se tornando.

Quem sabe, a partir destas reflexões propostas, o educador passe a questionar o porquê determinado aluno não está aprendendo, antes se estabelecer um diagnóstico pautado em patologias e rotulações?

O que se pretende é promover uma educação sem rotulações e patologizações, voltada à singularidade e não à homogeneidade, prova disto está no 
interesse em que estas publicações trazem de expor o fenômeno da medicalização como algo sério a ser discutido, além de propor reflexões para novas práticas de ensino e propostas de se desmedicalizar a educação.

\section{REFERÊNCIAS}

ALTMANN, H. Orientação sexual em uma escola: recortes de corpos e de gênero. Cadernos Pagu, v. 21, p. 281-315, 2003.

BELTRAME, M. M; BOARINI, M. L. Saúde Mental e Infância: Reflexões Sobre a Demanda Escolar de um Capsi. Psicologia: Ciência e Profissão, v. 33, n. 2, p. 336349, 2013.

CARVALHO, T. R. F; BRANT, L. C; MELO, M. B. de. Exigências de produtividade na escola e o consumo de metilfenidato. Educação e Sociedade, Campinas, v. 35, n. 127, p. 587-604, abr./jun. 2014.

COLLARES, C. A. L.; MOYSÉS, M. A. A. A Transformação do Espaço pedagógico em Espaço clínico (a patologização da educação). São Paulo: FDE, 1994. (Série Ideias, n. 23).

DECOTELLI, K. M; BOHRER, L. C. T; BICALHO, P. P. G. A Droga da obediência: Medicalização, Infância e Biopoder - Notas sobre clínica e política. Psicologia: Ciência e Profissão, v. 33, n. 2, 2013.

GUARIDO, R. A Medicalização do sofrimento psíquico: considerações sobre o discurso psiquiátrico e seus efeitos na Educação. Educação e Pesquisa, São Paulo, v. 33, n. 1, p. 151-161, jan./abr. 2007.

GUARIDO, R; VOLTOLINI, R. O que não tem remédio, remediado está?. Educação em Revista, Belo Horizonte, v. 25, n. 1, p. 239-263, abr. 2009.

HASHIGUTI, S. T. O Discurso médico e a Patologização da educação. Trabalho em Linguística Aplicada, Campinas, v. 48, n. 1, p. 41-51, jan./jun. 2009. 
HECKERT, A. L. C.; ROCHA, M. L. da. A Maquinaria escolar e os processos de regulamentação da vida. Psicologia \& Sociedade; v. 24, n. spe., p. 85-93, 2012.

MEIRA, M. E. M. Para uma crítica da Medicalização na educação. Revista Semestral da Associação Brasileira de Psicologia Escolar e Educacional, SP, v. 16, n. 1, jan./ jun. 2012.

MOYSÉS, M. A. A. Fracasso escolar: uma questão médica? Cadernos CEDES, São Paulo, n.15, p. 29-31, 1985.

MOYSÉS, M. A.; COLLARES, C. A. L. O Lado escuro da Dislexia e do TDAH. In: MEIRA, M. E. M.; TLESKI, S.; FACCI, M. (Org.). Exclusão e inclusão: falsas dicotomias. São Paulo: Casa do Psicólogo, 2009.

NAKAMURA, M. S. et al. Desvendando a queixa escolar: um estudo no Serviço de Psicologia da Universidade Federal de Rondônia. Revista Semestral da Associação Brasileira de Psicologia Escolar e Educacional, v. 12, n. 2, p. 423-429, jul./dez. 2008.

SIGNOR, R. Transtorno de Déficit de Atenção e Hiperatividade: uma análise histórica e social. RBLA, Belo Horizonte, v. 13, n. 4, p. 1145-1166. 2013.

TOASSA, G. Sociedade Tarja Preta: uma crítica à medicalização de crianças e adolescentes. Fractal, Rev. Psicol., v. 24, n. 2, p. 429-434, maio/ago. 2012.

VARGENS, O. M. da C.; PROGIANTI, J. M. O Processo de Desmedicalização da assistência à mulher no ensino de Enfermagem. Rev. Esc. Enferm. USP, v. 38, n. 1, p. 46-50, 2004.

Recebido em: 30 de agosto de 2017 Aceito em: 13 de novembro de 2017 